\title{
Predictive Control and Implementation of Mooring Automatic Positioning System for Deepwater Semi-Submersible Platform
}

\author{
Tao Sun, Wenbin Gui, Zhigang Yu, Zhimin Gao \\ No.704 Research Institute, CSIC, Shanghai, China \\ Email: qh0403@qq.com \\ Received 19 September 2014; revised 10 October 2014; accepted 18 October 2014 \\ Copyright (C) 2014 by authors and Scientific Research Publishing Inc. \\ This work is licensed under the Creative Commons Attribution International License (CC BY). \\ http://creativecommons.org/licenses/by/4.0/

(c) (i) Open Access

\begin{abstract}
The automatic positioning control of mooring system for deepwater semi-submersible platform has become a key issue in the research and development field of deep-sea resources. The DualStage Actuator (DSA) proposed in this paper can replace the single actuator to achieve the high speed and high precision positioning by cooperative control. The relative model and control algorithm of motion trajectory (CAMT) are designed and validated, which proves that the method proposed in this paper is effective.
\end{abstract}

\section{Keywords}

Deepwater Semi-Submersible Platform, Mooring System, Automatic Positioning, Anchor, Predictive Control

\section{Introduction}

With the development of deep-sea resources has become the focus of research [1], the automatic positioning control of mooring system for deepwater semi-submersible platform is raised as an important issue, in which, the big time delay, multi coupling, large vibration control problem are involved. The control strategy and high speed and high precision implementation of automatic positioning control mooring system are researched in this paper from the aspect of driving structure optimization control.

The simplified automatic positioning control systems for the deepwater semi-submersible platform are designed by the research institutes including Marin in Netherland and Marintek in Norway, in which, the PID control method is adopted and the control accuracy obtained is lower [2].

Jason I. Gobat and Mark A. GroSenbaug put forward an experiential model to explain the coupling relation 
between the surging of platform and the tension of mooring chain, and then developed a control strategy to achieve automatic positioning for the deepwater semi-submersible platform. However, the maximum error reached up to 11 percent [3].

Based on the given constraints of surging and swaying, Aubault (2007) presented a model and strategy to optimize the distribution and operation of anchors using the genetic algorithm, whereas, the control method for automatic positioning of mooring system is not involved from the perspective of process control for the platform [4].

The control strategy and development of automatic positioning control mooring system are researched in this paper from the aspect of predictive control, and a novel Smith-Fuzzy-PID predictive control strategy is proposed with comprehensive utilization of more accurate mathematical model analysis and rich operation experience knowledge, and the high accurate and stable control can be proposed and implemented for the mooring automatic positioning control system.

\section{Composition and Function of Automatic Positioning Control Mooring System for the Deepwater Semi-Submersible Platform}

By coordinating windlass and analog windlass simultaneously, automatic positioning control mooring system can simulate and control the movement of deepwater semi-submersible platform and balance the distribution of the force field.

The research object in this paper is the platform with four symmetric windlasses (12 anchor chains) to remain the platform stable in the horizontal direction as Figure 1. With the changes of the platform displacement, the angle of anchor chains is from $22.5^{\circ}$ to $67.5^{\circ}$.

In the deepwater mooring automatic positioning experiment and simulation systems, the real one anchor and the other three simulation anchors would be controlled by the center control desk. At the same time, the sea conditions and operating parameters of each anchor are shown in the human machine interface of the control desk. The simulation system to establish the dynamic model of anchor chain, platform, windlass, sea conditions to simulate the three sets of virtual windlass.

The system could simulate the platform control and movement, and balance the distribution of the force field, as shown in Figure 2, while the real anchor and analog anchors can be coordinated. During the automatic positioning operations of the multi-anchor, the system analyzes and processes the data, and hauls in and pays out the anchor by control command. In order to ensure the platform work security, the error of position which the offshore platform moves away from the goal position is less than the $5 \%$ depth of working field underwater. In the control process, the staff could monitor the parameters change of environmental loads, offshore platform, anchors by the human machine interface in real time.

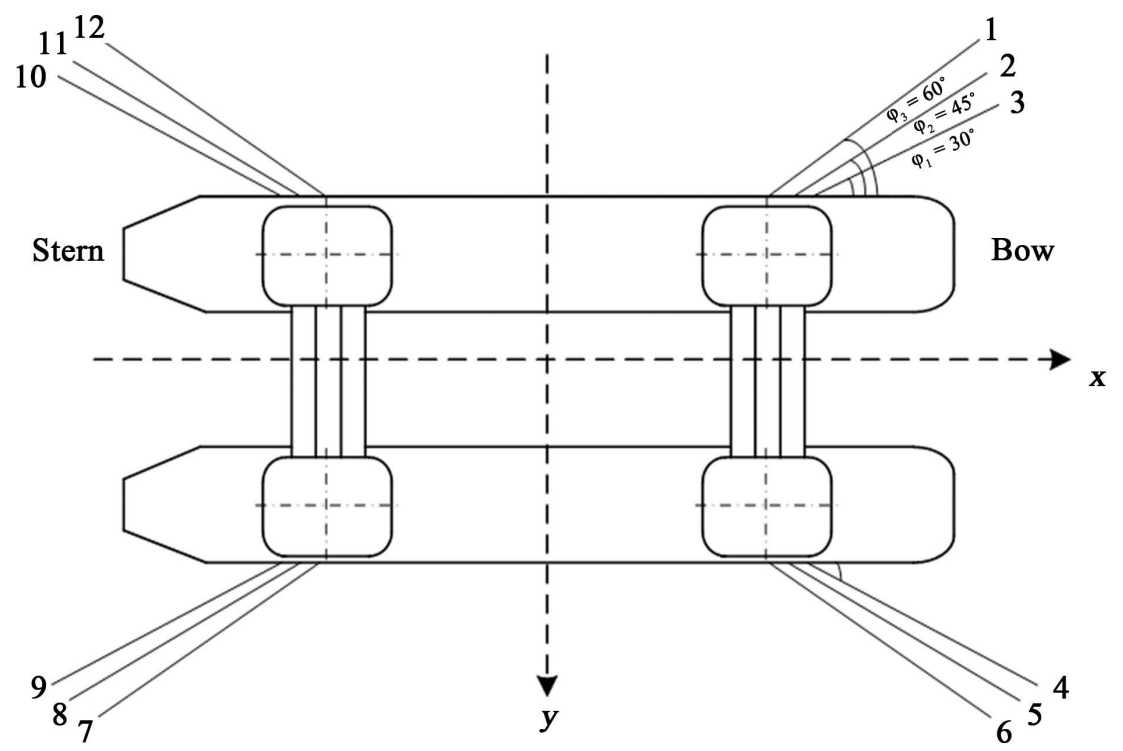

Figure 1. Anchor chain arrangement of deepwater platform. 


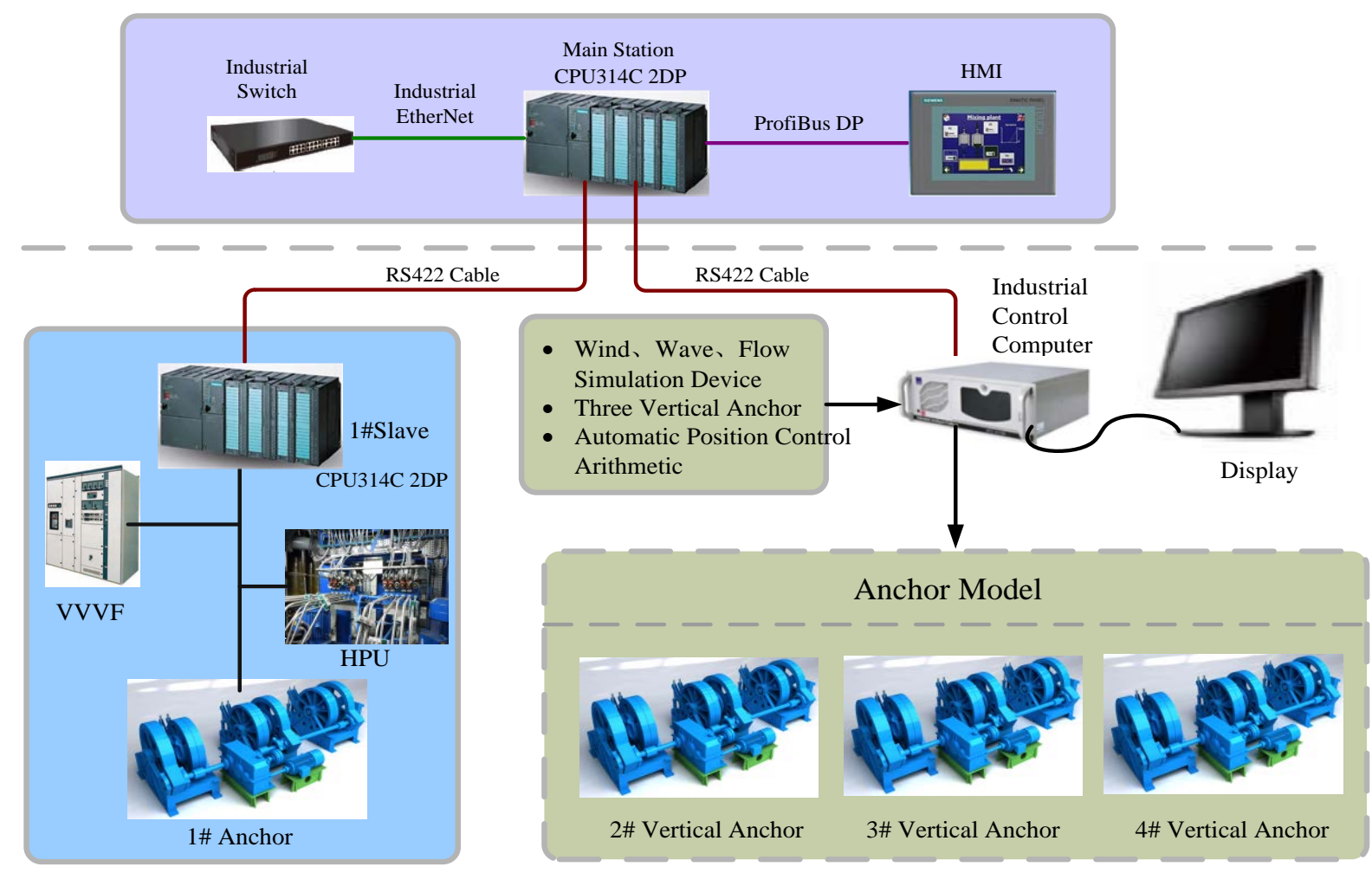

Figure 2. The composition of functional unit in mooring automatic positioning for deepwater semi-submersible platform.

The composition of functional unit is shown as Figure 2.

The automatic positioning control strategy for the plat form is shown in Figure 3. The PLC control system collects the running status and the parameters of the sensors and a physical anchor machine. The PLC control system and the simulation system adopt the RS422 protocol to transfer parameters. According to the control target of the platform, the simulation system analyzes and calculates the data of three analog anchors and a physical anchor, then send out the command and control each anchor.

In the control strategy, how to realize the automatic positioning is the key point, which should be further analyzed on the basis of the follows model analysis.

\section{Mathematical Model of the Mooring Automatic Positioning System}

\subsection{Dynamic Model of the Anchor Chain}

Dynamic characteristics of anchor chain greatly influence the movement of the deepwater platform. The anchor chain has the dynamic properties of the flexible components, and the dynamic model possesses features of uncertainty and nonlinear.

Considering the dynamical stiffness of anchor chain, 3-dimensional elastic rod theory is adopted to deduce the dynamic equation of the anchor chain [5]-[7]. The control equations can be expressed as follows:

$$
\begin{gathered}
M \ddot{r}+\left(B r^{\prime \prime}\right)^{\prime}-\left(\tilde{\lambda} r^{\prime}\right)^{\prime}=q \\
\frac{1}{2}\left(r^{\prime} \cdot r^{\prime}-1\right)-\frac{T}{\mathrm{EA}}=0
\end{gathered}
$$

where $M$ is mass matrix, $B$ is bending rigidity of anchor chain, $\lambda$ is effective tension of anchor chain, $T$ is tension of anchor chain, EA is axial rigidity and $q$ is the force on unit length of anchor chain.

As shown in the Figure 4 and Figure 5, we can get the following equation. 


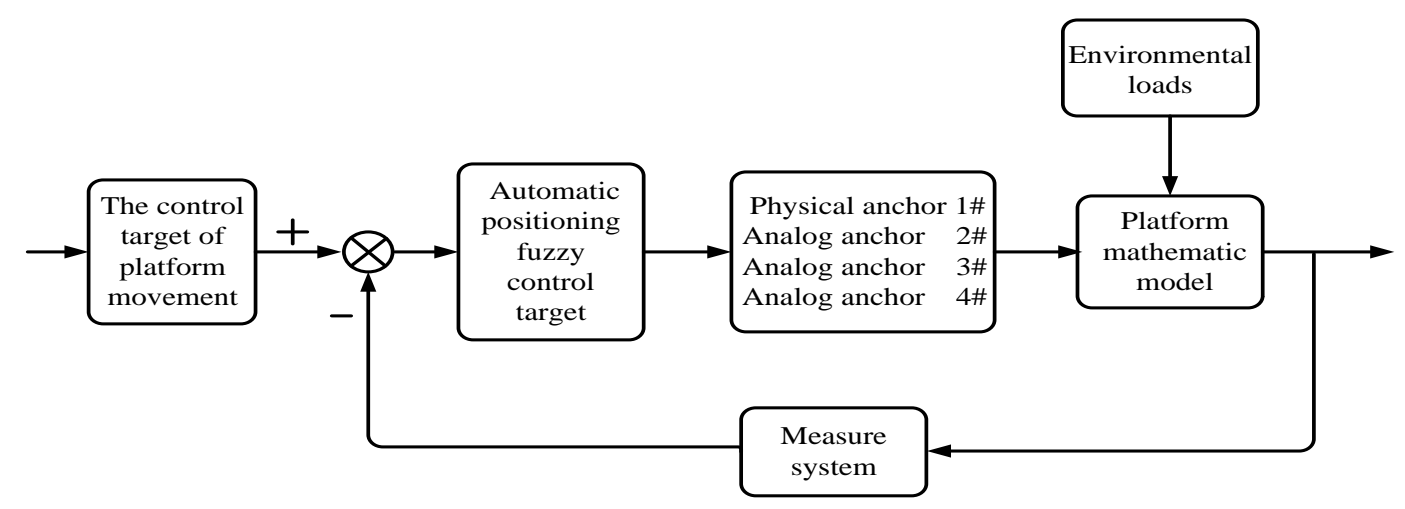

Figure 3. Automatic positioning control strategy for deepwater mooring.

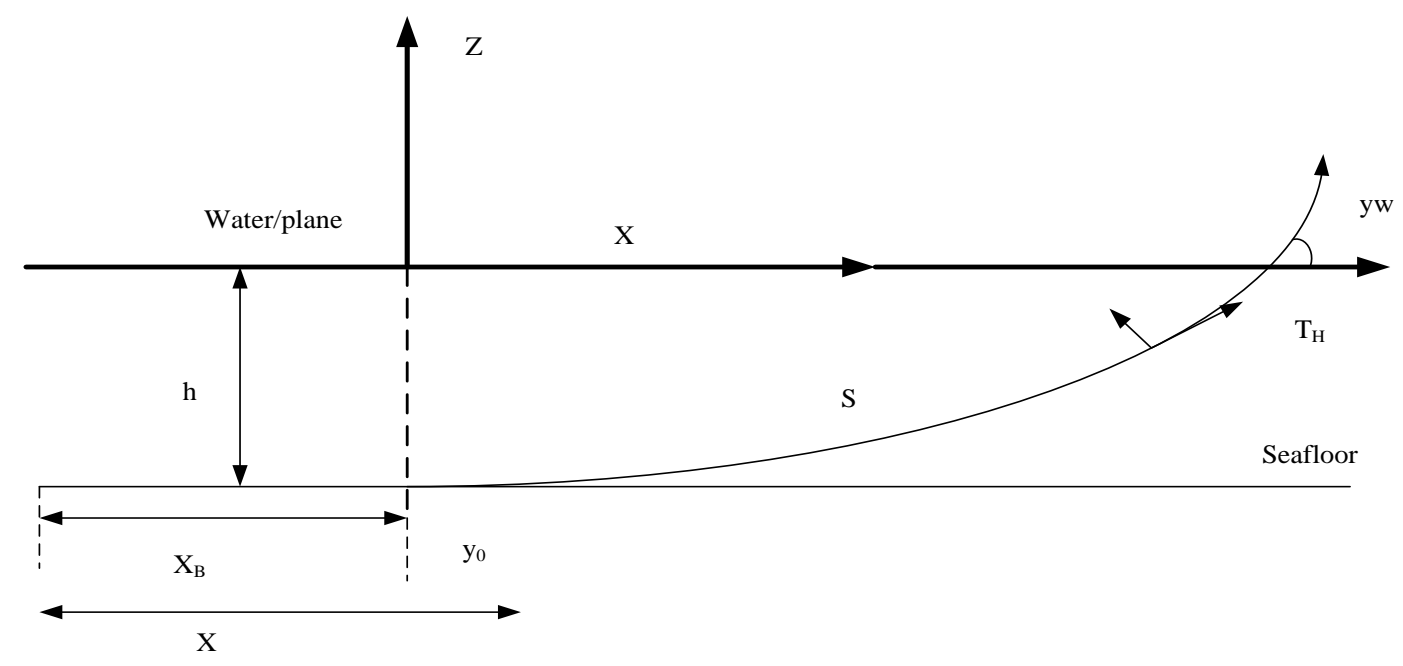

Figure 4. Single anchor chain simplified model.

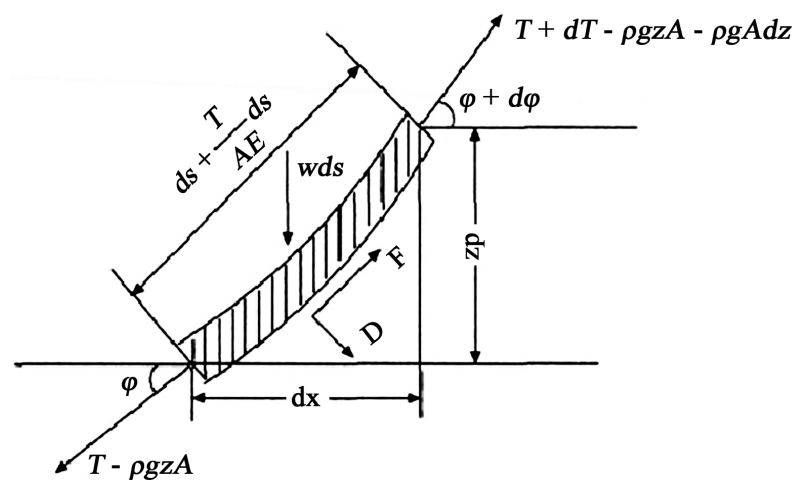

Figure 5. Force analysis on unit length of anchor chain.

$$
\begin{aligned}
\mathrm{d} T-\rho g A \mathrm{~d} z & =\left[w \sin \phi-F\left(\frac{T}{\mathrm{EA}}\right)\right] \mathrm{d} s \\
T \mathrm{~d} \phi-\rho g A z \mathrm{~d} \phi & =\left[w \cos \phi+D\left(1+\frac{T}{\mathrm{EA}}\right)\right] \mathrm{d} s
\end{aligned}
$$

The relationship between horizontal distance and vertical distance can be expressed with Equations (5) and (6). 


$$
\begin{gathered}
s=\frac{T_{H}}{w} \sinh \left(\frac{w X}{T_{H}}\right) \\
H=\left(\frac{T_{H}}{w}\right)\left[\cosh \left(\frac{w X}{T_{H}}\right)-1\right]
\end{gathered}
$$

The relationship between tension $T$ and wet weight $w$, length $s$ and depth $d$ can be expressed with Equation (7).

$$
T=\frac{w\left(s^{2}+d^{2}\right)}{2 d}
$$

The longitudinal component of chain tension is $T_{Z}=w s$.

The horizontal component of chain tension is $T_{H}=T \cos \phi_{w}$.

Basic constraint 1: The chain tension $T$ cannot exceed the set maximum value.

\subsection{Dynamic Model of the Windlass}

Taking the windlass as the research object, by reasonable simplification of the torque balance equation [5] [6], the controllable mathematical model of windlass can be expressed as Equation (8).

$$
J \frac{\mathrm{d}^{2} \theta}{\mathrm{d} t^{2}}+\beta \frac{\mathrm{d} \theta}{\mathrm{d} t}+k \theta+T_{z}=T_{d}
$$

where $J$ is the sum of the inertia and load, $\theta$ is step angle, $\beta$ is damped coefficient, $k$ is the relevant scale factor with $\theta, T_{z}$ is the sum of the frictional resistance moment and the irrelevant scale factor with $\theta, T_{d}$ is electromagnetic torque.

\subsection{Mathematical Model of Deepwater Platform}

High frequency movement of deepwater semi-submersible platform only shows the periodic oscillation and will not lead to the change of the average position. The nonlinear coupling for low frequency motion equation in the direction of surging [7]-[9], swaying and yawing can be expressed as follows.

$$
\begin{gathered}
\dot{\eta}=R(\psi) v \\
W \dot{v}+D v=\tau+R^{\mathrm{T}}(\psi) b
\end{gathered}
$$

where $\eta=[x, y, \psi]^{\mathrm{T}}$ is the platform position and angle vector under the fixed coordinate system, $v=[u, v, r]^{\mathrm{T}}$ is the velocity vector in three direction under the moving coordinate system, $R(\psi)$ is rotation matrix between the fixed coordinate system and the moving coordinate system, $W$ is $3 \times 3$ mass matrix, $D$ is damping matrix with the same dimension, $\tau=\left[F_{x}, F_{y}, F_{z}\right]^{\mathrm{T}}$ is the join forces(torque) of tension and environmental interference force in the three direction, $\mathrm{b}$ is the others environmental force(torque).

Basic constraint 2: In the process of mooring automatic positioning control, the changes of related parameters need to ensure the safety of the platform.

\section{The Analysis of System Control Model}

Control principle for mooring automatic positioning system for deepwater semi-submersible platform is aimed to securely satisfy the location accuracy requirement under the above 2 basic dynamic constraints. A closed-loop feedback mooring automatic positioning system is designed in this paper and the control block diagram as shown in Figure 3.

Set the controller output is $u(t)$, in the process of hauling in and paying out the anchor chain, motor action time is $T M=|u(t) / \omega|, \quad \omega$ is action time to angular displacement ratio of Stepper motor. 
In the process of automatic positioning, mooring position deviation calibration has certain hysteresis, due to the unsteady speed of hauling in and paying out the anchor chain, the error, the change of the coefficient of anchor chain tension and the speed of tension adjustment. Equation (11) can be obtained.

$$
y(t)=f(\theta) \cdot g\left(T_{m}\right)
$$

where $T_{m}$ is the time constant relevant with the above coefficients. Thus, the system has the following features:

- Uncertainty

The system contains many nonlinear factors, thus the exact theoretical mode cannot be determined.

- Hysteresis

According to Equation (11), system lags. The length of the lag time is relevant with deviation adjustment speed, the tension coefficient and the size of error.

- Big overshoot

With the existence of the lag factors, actual position deviation cannot be immediately eliminated after adjusting error for the first time and the system error should be adjusted once again, which leads to big overshoot. Correspondingly, system will be adjusted back in the same way, thus big overshoot and oscillation phenomenon appear.

\section{Control Strategy and Algorithm Implementation}

\subsection{Control Strategy}

There are many control algorithms for the lag system at present. The common control algorithm for mooring automatic positioning system is traditional digital PID, in which, control accuracy is limited. Based on the above model, a new comprehensive control strategy is proposed in this paper by combining PID, Fuzzy control and Smith predictive control.

\section{1) Fuzzy control}

Fuzzy control has simple algorithm, good performance and strong robustness [10] [11]. However, fuzzy control is not enough efficient for nonlinear and complex higher-order time-varying controlled object and should be combined with the other method [12]-[14], such as PID.

\section{2) Smith predictive control strategy}

There must be delay component $D_{\tau}(s)$ in the lag system, which will lead to the decrease of system stability. To improve the system stability, a compensator $D_{\tau}(s)$ is placed in parallel with the original controller $D(s)$ in the Smith predictive control strategy, which makes that equivalent object after compensation does not contain pure hysteresis characteristics [15]-[17]. The pure lag compensation controller is shown as Figure 6, where, $D_{\tau}(s)$ is equal to $G_{0}(s)\left(1-\mathrm{e}^{-\tau s}\right)$, and transfer function can be expressed with Equations (12) and (13).

$$
\begin{gathered}
D_{g}(s)=\frac{U(s)}{E(s)}=\frac{D(s)}{1+D(s) G_{0}(s)\left(1-\mathrm{e}^{-\tau s}\right)} \\
H(s)=\frac{D(s) G_{0}(s) \mathrm{e}^{-\tau s}}{1+D(s) G_{0}(s)}
\end{gathered}
$$

The system output is relevant with the input in the future time. A certain predictive mechanism is needed to obtain the future input to realize the efficient control.

3) A new comprehensive predictive control strategy is proposed in this paper.

From Equation (13), an equivalent system model can be obtained as Figure 7.

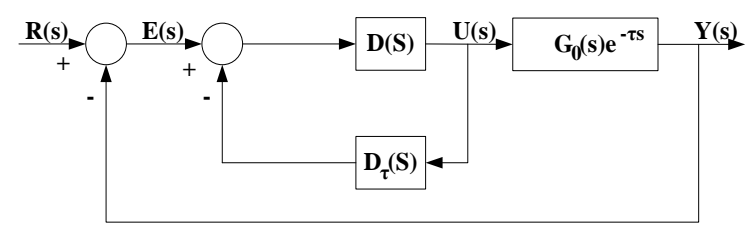

Figure 6. The pure lag compensation controller. 


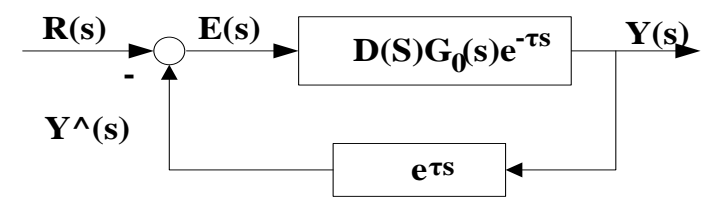

Figure 7. An equivalent system mode in Smith predictive control strategy.

where $Y^{\wedge}(s)=\mathrm{e}^{\tau s} Y(s)$, by series expansion, transform to the time domain and discretization for $\mathrm{e}^{\tau s}$, Equation (14) can be obtained.

$$
\begin{aligned}
y^{\wedge}(k) & =y(k)+\tau \frac{y(k)-y(k-1)}{T}+\frac{\tau^{2}}{4} \frac{y(k)-2 y(k-1)+y(k-2)}{T}+\cdots \\
& =a(0) y(k)+a(1) y(k-1)+a(2) y(k-2)+\cdots a(n) y(k-n)+\cdots
\end{aligned}
$$

where $k$ is sampling instant, $k=0,1,2, \cdots, T$ is sampling period, $y(k)$ is the output value on the sampling instant, $y^{\wedge}(k)$ is the feedback value on the sampling instant, $a(n)$ is the equivalent coefficient of $y(k-n)$, which are both constants relevant with time delay $\tau$.

From Equation (14), compared with Smith predictive control, the new comprehensive predictive control strategy can inherit the advantages of Smith predictive control and overcome the dependence on the precise mathematical model of the system.

\subsection{Algorithm Implementation Based on the Control Model}

The Smith-PID control model and Smith-Fuzzy control model are analyzed at first, the new integrated comprehensive control model is then proposed in this part.

\section{1) Smith-PID control model}

Combining the Smith predictive control and PID control, the Smith-PID control can compensate the pure lag system like Smith predictive control and is easy to realize as PID control, which is shown as Figure 8.

The disadvantage of Smith-PID control model is that the controller includes the precise mathematic model, which is difficult to realize for the research object in this paper. Thus, the Fuzzy control strategy is introduced to Smith predictive control model.

2) Smith-Fuzzy control model

The Smith-Fuzzy controller deals with the time-varying system and compensates the pure lag characteristic simultaneously. The Smith-Fuzzy control model and controller are shown as Figure 9 and Figure 10 respectively.

In Figure 10, GE, GC, GU is Error quantification factors, the variety rate of error quantification factors and output scale factor in turn.

As shown in Figure 1, No.3 windlass (No.7, 8, 9 anchor chain) hauls in chain and No.1 windlass (No.1, 2, 3 anchor chain) pays out chain while the platform moves to the positive direction along the $x$ and $y$ axis. The operation of the No.2 and the No.4 windlass should be determined by the size of displacement deviation of surging and swaying. No.4 windlass (No.10, 11, 12 anchor chain) hauls in chain and No.2 windlass (No.4, 5, 6 anchor chain) pays out chain while displacement deviation of surging is large.

The domain of discourse of input displacement deviation is $[(-6,-6),(-6,-6)]$ in Fuzzy control system for the platform in this paper, which is swaying displacement deviation and surging displacement deviation in turn. And the fuzzy subset is $\{$ NL, NM, NS, ZE, PS, PM, PL $\}$, where, NL (negative large), NM (negative medium), NS (negative small), ZE (zero), PS (positive small), PM (positive medium), PL (positive large) are the membership functions value. The domain of discourse of output movement is $[(-6,-6,-6,-6),(-6,-6,-6,-6)]$, which is displacement of the No.1-4 windlass in turn. And the fuzzy subset is also $\{$ NL, NM, NS, ZE, PS, PM, PL\} . (Table 1).

Mamdani method is adopted in Fuzzy rules, the fuzzy sets would be translated into the clear value to represent 


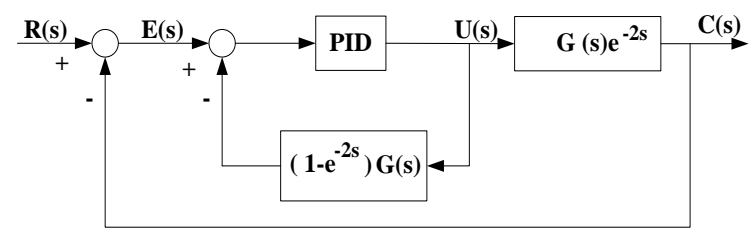

Figure 8. Smith-PID control model.

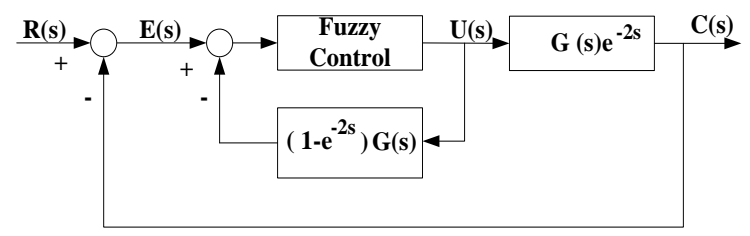

Figure 9. Smith-Fuzzy control model.

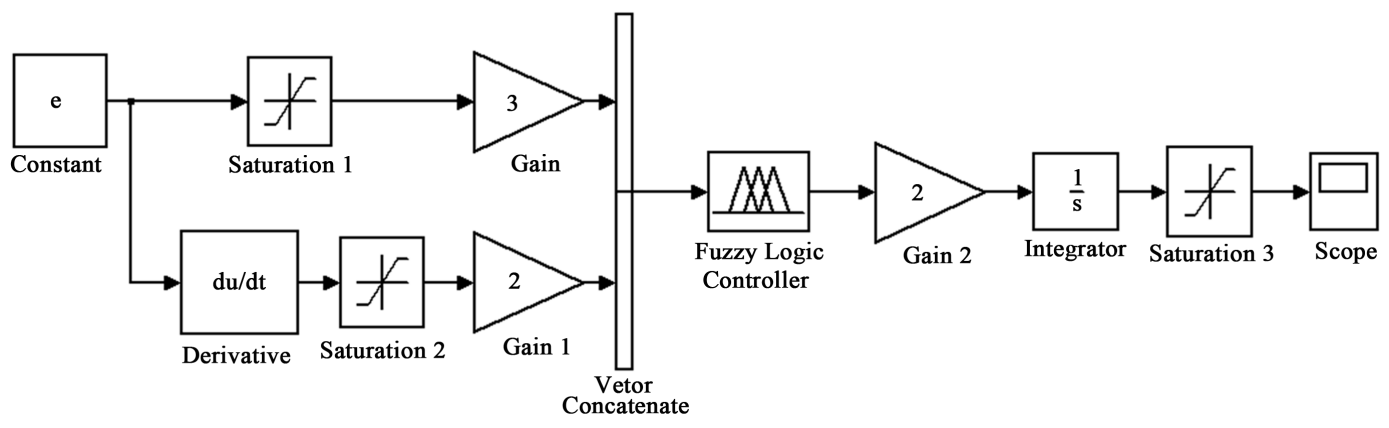

Figure 10. Smith-Fuzzy controller.

Table 1. Fuzzy control rules table.

\begin{tabular}{cccccccc}
\hline Surge Sway & NL & NM & NS & ZE & PS & PM & PL \\
\hline NL & NL/NL & NM/NL & NS/NL & ZE/NL & PS/NL & PM/NL & PL/NL \\
NM & NL/NM & NM/NM & NS/NM & ZE/NM & PS/NM & PM/NM & PL/NM \\
NS & NL/NS & NM/NS & NS/NS & ZE/NS & PS/NS & PM/NS & PL/NS \\
ZE & NL/ZE & NM/ZE & NS/ZE & ZE/ZE & PS/ZE & PM/ZE & PL/ZE \\
PS & NL/PS & NM/PS & NS/PS & ZE/PS & PS/PS & PM/PS & PL/PS \\
PM & NL/PM & NM/PM & NS/PM & ZE/PM & PS/PM & PM/PM & PL/PM \\
PL & NL/PL & NM/PL & NS/PL & ZE/PL & PS/PL & PM/PL & PL/PL \\
\hline
\end{tabular}

after fuzzy reasoning, namely "anti-fuzzy”. Anti-fuzzy uses the center of gravity method, that is, to find the center of area surrounded by the subjection function curve and the abscissa. The abscissa value of the center is selected as the representative of the value of the fuzzy sets.

3) A new Smith-Fuzzy-PID predictive control strategy implementation

According to the above analysis, combining the Smith-PID control and Smith-Fuzzy control, with some approximate equivalent processing for Smith predictive control, that is, take the $\mathrm{d}$ steps sliding average of the historical data before the sampling instant of system output to predict the feedback value of the current sampling instant, Equation (15) can be obtained.

$$
y^{\wedge}(k)=a(0) y(k)+a(1) y(k-1)+\cdots a(d) y(k-d)
$$

where $d$ value is larger, the more accurate prediction. 
The new comprehensive predictive control algorithm inherits the advantages of Smith predictive control and overcomes the dependence on the precise mathematical model of the system. The comprehensive predictive control algorithm structure is shown as Figure 11.

The predictive weight of feedback channel $\{a(n)\}$ can be off-line identified by system output values and can be also on-line optimized.

\section{Analysis of Simulation Result}

According to the environmental condition every year, considering the most unfavorable situation with the wind wave and current in the same direction, and taking $600 \mathrm{~s}$ as computation time, $14 \mathrm{~m}$ is taken as the desired value of platform displacement in the $1500 \mathrm{~m}$ water depth and wave direction Angle (135). The simulation result with and without mooring damp with the traditional mooring positioning PID control strategy is shown as Figure 12 [18]. And the simulation displacement of the platform with the new comprehensive predictive control algorithm is shown as Figure 13. It is obvious seemed that the overshoot decreases and the adjustment process is accelerated.

\section{Development of Monitoring System Integrated Software and Hardware}

\subsection{The Master Monitoring System}

Four mooring equipments are centralized monitored on the central control desk [19] [20]. All 12 anchor chains status and real-time sea conditions are obtained and displayed on the HMI as shown in Figure 14.

During the course of the multi-point mooring position operation, the deepwater mooring position system to be used to simulate the environment and equipment parameters. After analysis and treatment, the central control system sends out the correction command to pay out or haul in anchor chain. In order to ensure the safety of the platform, the platform movement would be limited in less than $5 \%$ the working depth of water. In the control process, the environmental load, the platform data and the anchor parameters would be showed on the HMI in real-time.

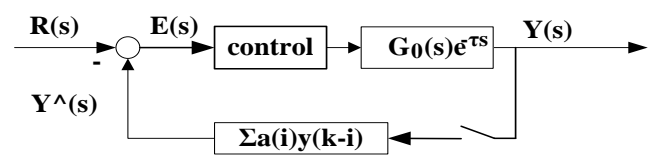

Figure 11. Predictive control-equivalent smith-fuzzy-PID algorithm structure.

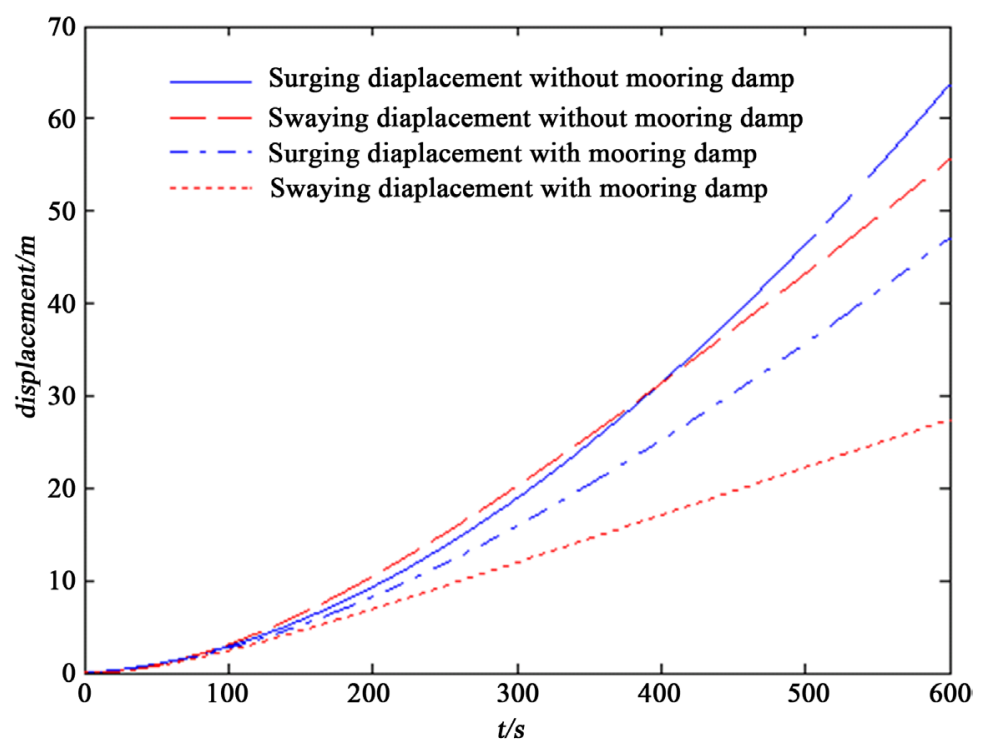

Figure 12. Displacement of platform with traditional control strategy. 


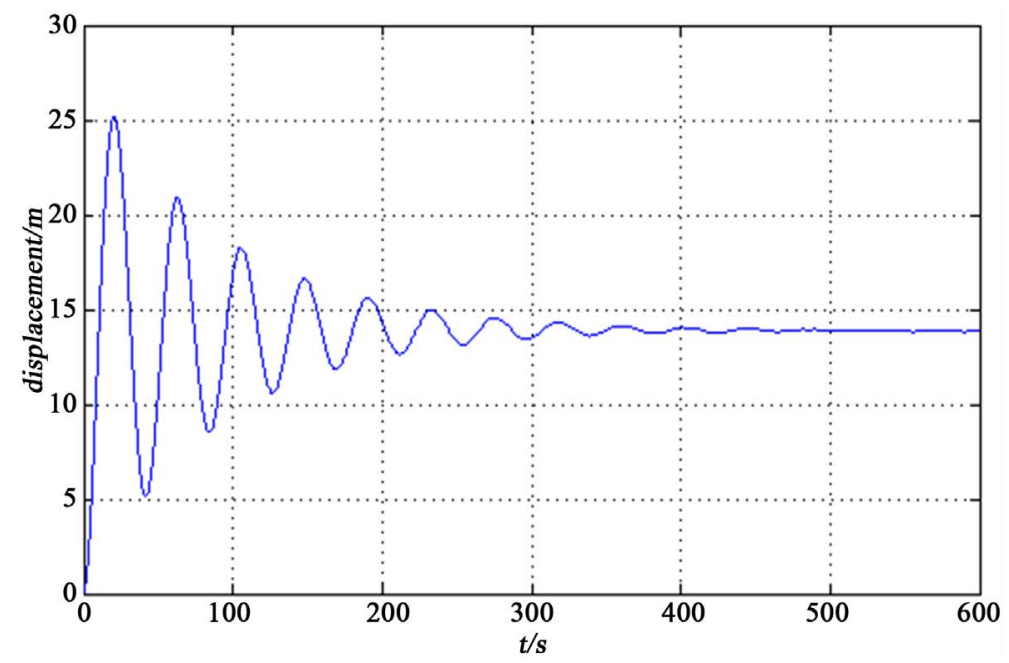

Figure 13. Displacement of platform with new control strategy.

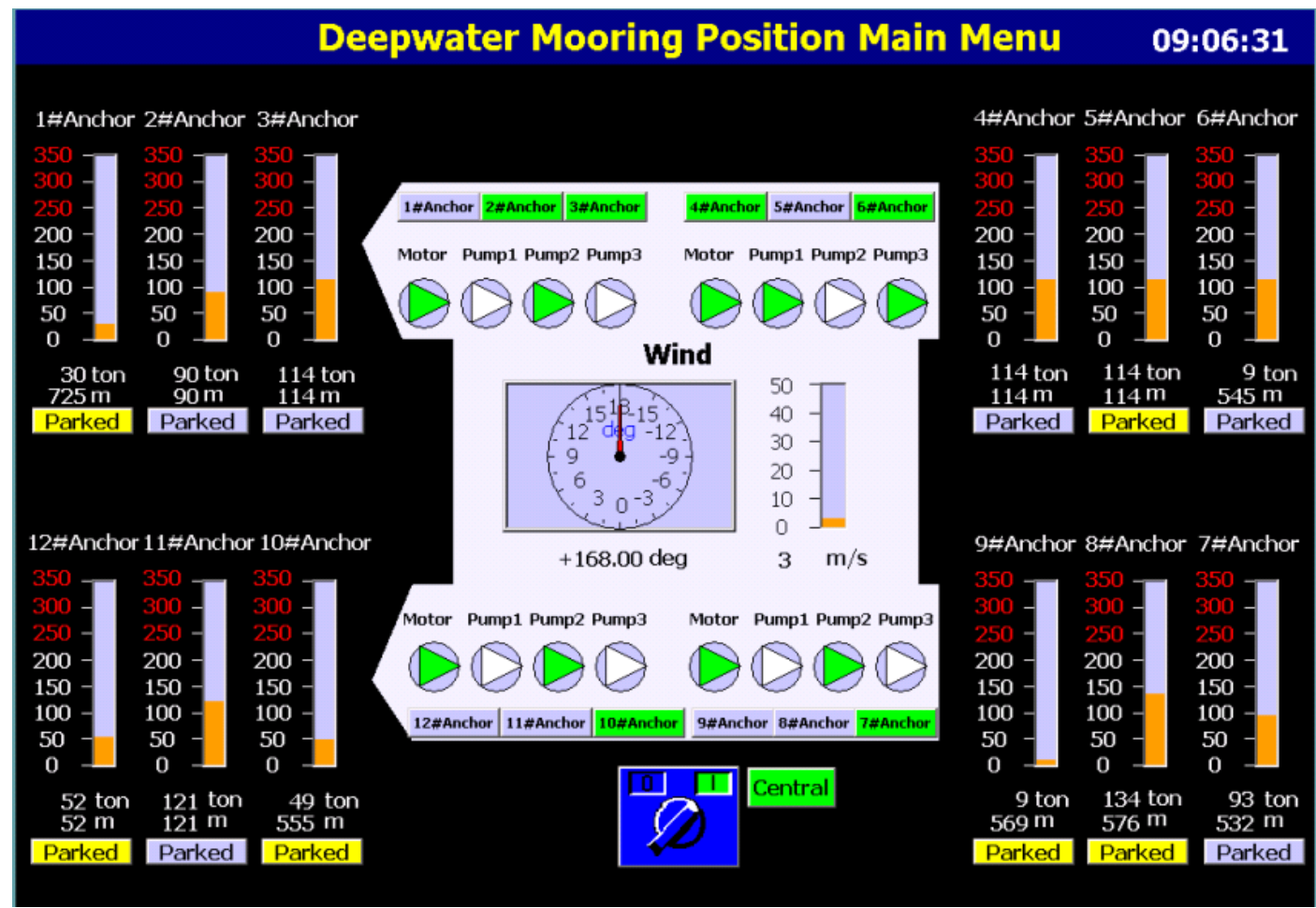

Figure 14. Main monitoring menu of four mooring position system.

When the tension of the anchor chain reaches its maximum, the control system should take protective measures, and send out alarm signals to prevent the accidents.

As shown in Figure 14, the main menu is divided into five regions,, which including the four corner regions and a central region. The four corners area are used for monitoring four anchors in the four corners of the platform, each anchor contains three capstans. The tension of anchor chain, the length of anchor chain and the status of capstan can be seen in the menu.

\subsection{The Monitor System Design of Anchor}

Adopting the touch screen operation of panel, each anchor can be monitored and operated by the center control 
desk, which can realize the anchor chain choose, the anchor chain mode selection, the anchor chain speed selection, the anchor chain pay out and haul in, the anchor chain emergency release, the sea conditions detection and the equipment status monitoring [21].

During the operation of anchor chain, selecting the corresponding anchor chain, the work mode, the run speed, the pay out and haul in of anchors chain are operated by the joystick which mounted on the control desk. The related parameters about the anchors and platform can be displayed on the HMI.

\section{Conclusions}

According to the above analysis and simulation, adopting the new comprehensive Smith-Fuzzy-PID predictive control algorithm proposed in this paper, the overshoot decreases and the adjustment process is accelerated, and the performance of the mooring automatic positioning system is greatly improved for deepwater semi-submersible platform.

The utility system is developed to realize accurately automatic positioning under satisfying the dynamic constraints and has alarm protection functions by the central control, on-site control and monitoring.

Thus, the control strategy and the monitoring system integrated software and hardware are validated to have the ability to play an important guiding role on the development of marine engineering.

\section{Acknowledgements}

This research was financially supported by the marine engineering equipment scientific research project of National Ministry of Industry and Information Technology of China (Department of Industry and Information Technology Equipment [2009] 91).

\section{References}

[1] Sun, T., Gui, W.B. and Yu, Z.G. (2012) Semi-Submersible Platform Positioning Mooring Control Test System Design and Application. Marine Engineering, 84-86.

[2] Yang, H. (2012) Research on DP Simulated Operating System for a Deep Sea Semi-Submersible Drilling Platform. Shanghai Jiao Tong University Library, Shanghai, 6-8.

[3] Gobat, J.I. and Grosenbaugh, M.A. (2001) A Simple Model for Heave-Induced Dynamic Tension in Catenary Moorings. Applied Ocean Research, 159-174.

[4] Hu, Z.Q. (2008) Design and Manufacture of Naval Architecture and Ocean Structure. Shanghai Jiao Tong University Library, Shanghai, 5-8.

[5] Huang, S. (1994) Dynamic Analysis of 3-D Marine Cables. Ocean Engineering, 21, 587-605. http://dx.doi.org/10.1016/0029-8018(94)90008-6

[6] Van den Boom, H.J.J., Dekker, J.N. and Van Elsacker, A.W. (1987) Dynamic Aspects of Offshore Riser and Mooring Concepts.

[7] Bliek, A. (1984) Dynamic Analysis of Single Span Cables. Ph.D. Thesis, MIT, Cambridge.

[8] Triantafyllou, M.S., Bliek, A. and Shin, S. (1985) Dynamic Analysis as a Tool for Open-Sea Mooring System Design. Transactions SNAME, 93, 303-324.

[9] Thomas, D. and Hearn, G.E. (1994) Deepwater Mooring Line Dynamics with Emphasis on Sea-Bed Interference Effects. Offshore Technology Conference, 3, 203-241.

[10] Wen, X., Zhou, L. and Li, D.J. (2001) MATLAB Fuzzy Toolbox Analysis and Application. Science Press, Beijing.

[11] Wu, X.L. and Lin, Z.H. (2002) MATLAB Auxiliary Fuzzy System Design. Xi’an Electronic Science and Technology University Press, Xi'an.

[12] Bamieh, B., Paganini, F. and Dahleh, M. (2002) Distributed Control of Spatially Invariant System. IEEE Transactions on Automatic Control, 47, 1091-1107. http://dx.doi.org/10.1109/TAC.2002.800646

[13] Rad, A.B., Lo, W.L. and Tsang, K.M. (2003) Simultaneous Online Identification of Rational Dynamics and Time Delay: A Correlation-Based Approach. IEEE Transactions on Control Systems Technology, 11, 957-959. http://dx.doi.org/10.1109/TCST.2003.819594

[14] Layne, J.R. and Passino, K. (1993) Fuzzy Model Reference Learning Control for Cargo Ship Steering. IEEE Control Systems, 13, 23-34. http://dx.doi.org/10.1109/37.248001

[15] Shi, J., Ma, L. and Chen, G.H. (2012) Design and Simulation of Improved Smith Predictive Controller. Journal of Ap- 
plication World, 37, 56-58.

[16] Astrom, K.J., Hung, C.C. and Lim, B.C. (1994) A New Smith Predictor for Controlling a Process with an Integrator and Long Dead Time. IEEE Transactions on Automatic Control, 39, 343-345. http://dx.doi.org/10.1109/9.272329

[17] Kaya, I. (2001) Improving Performance Using Cascade Control and a Smith Predictor. ISA Transactions, 40, $223-234$. http://dx.doi.org/10.1016/S0019-0578(00)00054-9

[18] Yao, X.C. (2009) Research on Semi-Physical Simulation of Mooring Dynamic Positioning for Semi-Submersible Platform. Harbin Engineering University Library, Harerbin, 58-60.

[19] Siemens AG, Automation and Drives Group (2008) Siemens Touch Screen Selection of Sample Manual. Beijing.

[20] Wang, N. and Wu, L.T. (2009) Analysis Siemens Man-Machine Interface. Beijing University of Aeronautics and Astronautics Press, Beijing.

[21] Wen, X., Zhou, L. and Li, D.J. (2001) MATLAB Fuzzy Toolbox Analysis and Application. Science Press, Beijing. 
Scientific Research Publishing (SCIRP) is one of the largest Open Access journal publishers. It is currently publishing more than 200 open access, online, peer-reviewed journals covering a wide range of academic disciplines. SCIRP serves the worldwide academic communities and contributes to the progress and application of science with its publication.

Other selected journals from SCIRP are listed as below. Submit your manuscript to us via either submit@scirp.org or Online Submission Portal.
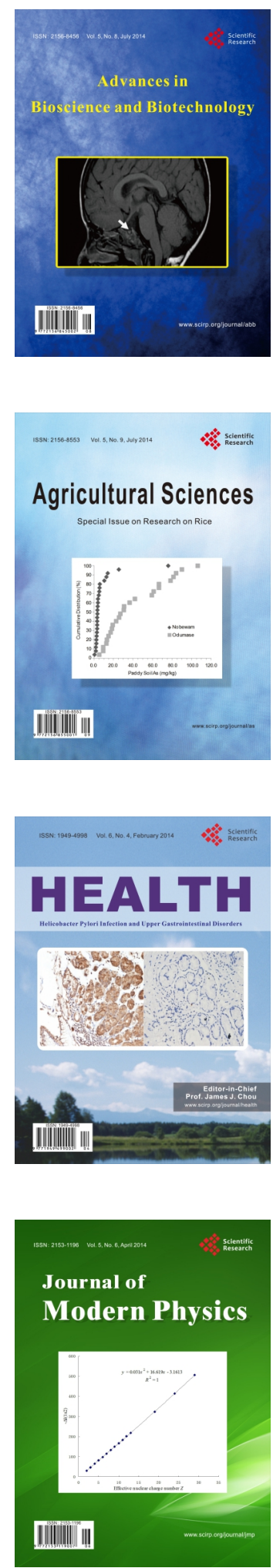
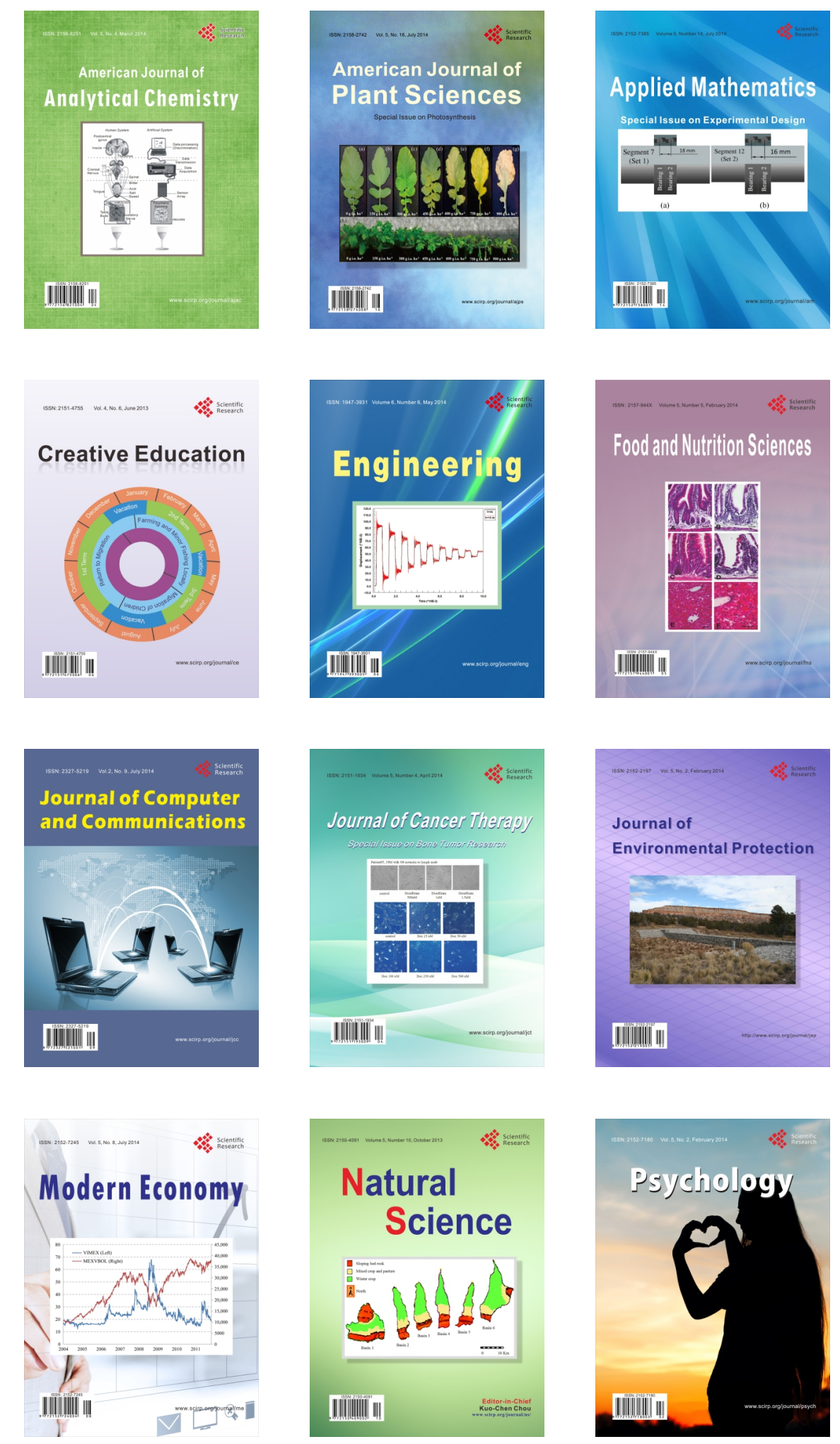